Archived version from NCDOCKS Institutional Repository http://libres.uncg.edu/ir/asu/

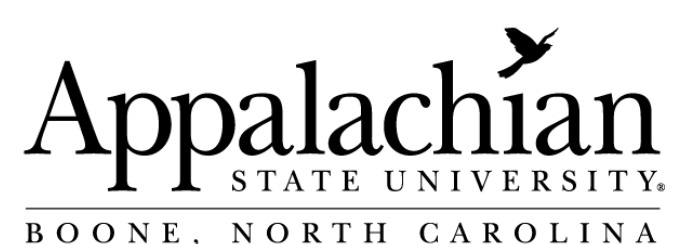

\title{
A Comment On “Three Reasons To Use Annual Payments In Contingent Valuation"
}

\author{
By: John C. Whitehead
}

\begin{abstract}
Egan, Corrigan and Dwyer (2015) conduct a survey of Ohio residents and collect contingent valuation method data for a wetlands restoration project. The CVM scenario includes a split sample treatment where payment schedules differ. My analysis of these data suggests that there is little evidence of theoretical validity in the data and "fat tails" is a significant problem.
\end{abstract}

Whitehead, J. C. (2018). "A comment on "Three reasons to use annual payments in contingent valuation"." Journal of Environmental Economics and Management 88: 486-488. https://doi.org/10.1016/j.jeem.2016.09.004. Publisher version of record available at: https://www.sciencedirect.com/science/article/pii/S0095069616302911 


\title{
A comment on "Three reasons to use annual payments in contingent valuation"
}

\author{
John C. Whitehead ${ }^{1}$ \\ Department of Economics, Appalachian State University, Boone, NC 28608, USA
}

\begin{abstract}
A B S T R A C T
Egan, Corrigan and Dwyer (2015) conduct a survey of Ohio residents and collect contingent valuation method data for a wetlands restoration project. The CVM scenario includes a split sample treatment where payment schedules differ. My analysis of these data suggests that there is little evidence of theoretical validity in the data and "fat tails" is a significant problem.
\end{abstract}

Keywords:

Contingent valuation method

Payment schedule

Willingness to pay

Egan, Corrigan and Dwyer (ECD, 2015) conduct a survey of Ohio residents and collect contingent valuation method (CVM) data for a wetlands restoration project. The CVM scenario in ECD provides a split sample treatment where payment schedules differ. They estimate lower bound willingness to pay (WTP) with the Turnbull nonparametric estimator and find that it is equal to $\$ 18, \$ 24$ and $\$ 47$ from perpetual annual, ten annual and one-time payment schedules. ${ }^{2}$ They use these results and argue that one reason to use a perpetual annual payment schedule over the others is that the perpetual annual payment schedule CVM data are convergent valid with the consumer surplus estimated with the travel cost method. The one-time payment schedule data are not convergent valid.

My analysis of these data, constructed from the summary in ECD's Table 2, suggests that there is little evidence of convergent validity between the WTP from the perpetual annual payment schedule and contingent behavior data. These data suffer from (a) a non-monotonic relationship between the bid amount and percentage yes responses and (b) fat tails (Parsons and Kelly, 2016). Even with the best behaved dichotomous choice CVM data adopting different assumptions for the distribution of WTP can lead to a wide range of WTP estimates (e.g., Boman et al., 1999). The range of reasonable WTP estimates widens with problems (a) and (b). Choosing only one of the potential WTP estimates (e.g., lower bound Turnbull) from the potential range for comparison to the consumer surplus estimate from the travel cost method is not appropriate for a convergent validity test. The Turnbull estimator chosen by ECD is the lowest in the potential range and this drives the

E-mail address: whiteheadjc@appstate.edu

1 The author would like to thank Tim Haab, Fredrik Carlsson and an anonymous referee for comments that have greatly improved this paper.

${ }^{2}$ When comparing the perpetual annual and one-time payments the WTP values imply a $38 \%$ discount rate. The formula used is: 
conclusion of convergent validity. ${ }^{3}$

Casual observation of ECD's Table 2 suggests that the yes responses may be insensitive to bid values. A chi-square test for differences in frequencies for the ten annual payments schedule find that there are no differences at the $p=0.27$ level. The chi-square statistics are statistically significant at the $p=0.02$ and $p=0.01$ levels for the perpetual annual and one-time payment schedule treatments so we focus on these. I conduct differences in proportions tests for percentage "yes" responses comparing consecutive bid values. ${ }^{4}$ For example, with the perpetual annual payment schedule, is $70 \%$ yes at a $\$ 5$ bid value significantly greater than $58 \%$ yes at $\$ 10$ ? Since there are eight bid values in each payment schedule treatment there are 14 pairwise comparisons over consecutive bid amounts. Only 8 of the 14 comparisons have the correct sign predicted by theory. Only two of the 8 comparisons with correct sign produce $z$-statistics that indicate statistically significant differences at the $90 \%$ confidence level in one tailed tests (the critical $z$ value is 1.282 ). These are: (1) the $53 \%$ yes response at the $\$ 30$ bid value is significantly greater than the $30 \%$ yes response at the $\$ 40$ bid value in the perpetual annual payment schedule and (2) the $33 \%$ yes response at $\$ 100$ is significantly greater than the $16 \%$ yes response at the $\$ 120$ bid value in the one-time payment schedule.

The bid values in ECD are tight relative to others found in the CVM literature so it is not unexpected that there are few differences in yes responses in consecutive bid values. Sensitivity to bid may also be found in the non-consecutive bid values. For example, with the perpetual annual payment schedule, is $70 \%$ yes at a $\$ 5$ bid value significantly greater than $49 \%$ yes at \$15? There are 21 additional non-consecutive difference in proportions tests for each of the two payment schedules. Seven of the 42 non-consecutive comparisons have the incorrect sign. For the perpetual annual payment schedule, 6 of the $19 z$-statistics with the correct sign are greater than the critical value at the $90 \%$ level for a one-tailed test. Five of the six involve the $\$ 40$ bid value: $\$ 25$ vs. $\$ 40, \$ 20$ vs. $40, \$ 15$ vs. $40, \$ 10$ vs. $\$ 40$ and $\$ 5$ vs. $\$ 40$. The remaining significant difference in yes responses is found when comparing the lowest and highest bid values: $\$ 5$ vs. $\$ 50$. For the one-time payment schedule, 7 of the $16 z$-statistics with the correct sign are greater than the critical value at the $90 \%$ level for a one-tailed test. Four of these involve the $\$ 120$ bid value: $\$ 80$ vs. $\$ 120, \$ 60$ vs. $\$ 120, \$ 40$ vs. $\$ 120$ and $\$ 20$ vs. $\$ 120$. The other three differences are $\$ 60$ vs. $\$ 100, \$ 60$ vs. $\$ 160$ and $\$ 20$ vs. $\$ 160$.

The Turnbull nonparametric WTP estimate is the area under the step function formed by the unconditional probability of a yes response at each bid amount. When the unconditional probability of a yes response is not monotonically decreasing the probability of a yes response is pooled back to the lowest bid amount over the range of non-monotonically increasing bid amounts. In contrast, the Kriström (1990) nonparametric WTP estimate is the area under the demand function formed by assuming a probability of a yes response of one at a zero bid, using linear interpolation to determine an estimate of the bid amount that leads to a probability of zero (i.e., the choke price) and using linear interpolation for the slope of the survival function between bid amounts. Also, bids are not pooled back to the minimum bid amount when the probability of a yes response is not monotonically decreasing. Instead, the pooled probability is applied over the non-monotonic bid range. ${ }^{6}$

These differences are illustrated in Fig. 1 for the annual payment schedule using data from ECD's Table 2. The Turnbull survival function lies below the Kriström survival function for the reasons described above: (1) the ECD Turnbull function for bid amounts $\$ 15, \$ 20, \$ 25$ and $\$ 30$ are pooled back to $\$ 15$ and bid amounts $\$ 40$ and $\$ 50$ are pooled back to $\$ 40$, (2) the ECD survival function is truncated at $\$ 40$ and (3) the Kriström choke price is estimated at $\$ 75$ and the probability yes at the zero bid amount is assumed to be $100 \%$. The Turnbull and Kriström WTP estimates are $\$ 17.91$ (s.e. $=0.98$ ) and $\$ 30.06$ (s.e. $=$ $1.73) .^{7}$ Pooling back of bid amounts accounts for $46 \%$ ( $\left.\$ 5.70\right)$ of the $\$ 12.15$ difference in WTP estimates and truncation at the highest bid amount (i.e., the fat tail problem) accounts for 37\% (\$4.50) of the difference. Linear interpolation between bid amounts accounts for $16 \%$ ( $\$ 1.95)$ of the difference in WTP estimates.

The travel cost method estimate of annual consumer surplus is $\$ 19$ with a $95 \%$ confidence interval of $(\$ 14, \$ 24)$. Using the Kriström estimates the annual payment WTP estimate is \$11 greater than the consumer surplus estimate and the 95\% confidence intervals do not overlap. Therefore, there is no convergent validity between the travel cost and contingent valuation method with this alternative WTP estimate from the annual payment schedule. ${ }^{8}$ The Turnbull and Kriström WTP estimates for the one-time payment schedule are $\$ 47.20$ (s.e. $=1.71$ ) and $\$ 90.37$ (s.e. $=7.79$ ), respectively. The WTP estimate from the Kriström estimator using the one-time payment data is convergent valid with the travel cost method consumer surplus estimate at a discount rate of $21 \%$.

My analysis of the ECD data finds that there are only a few statistically significant differences in the percentage of yes responses across bid amounts for each of the payment schedules. This result is in contrast with what is found in much of the

(footnote continued)

one - time WTP $=$ perpetual annual WTP $\div$ discount rate.

3 The Turnbull WTP is not an estimate of expected WTP but rather a lower bound on expected WTP calculated from any non-negative distribution. As such, interpreting the Turnbull lower bound as an estimate of expected WTP for a convergent validity test is not valid.

4 These results are available upon request.

${ }^{5}$ When the $\$ 40$ bid value is deleted from the perpetual annual payment schedule data the chi-square test statistic for independence in frequencies is not statistically significant at the $p=0.10$ level. Considering the one-time payment schedule, when the $\$ 120$ bid value is deleted the frequency test statistic is not statistically significant at the $p=0.10$ level.

6 The Turnbull and Kriström WTP estimates are described in detail by Haab and McConnell (2002).

7 The Kriström WTP estimate is found using the DCchoice package in R (Aizaki et al., 2015) and the standard error is found as in Boman et al. (1999)

8 The implied discount rate from comparing the WTP estimates with annual and one-time payment schedules is $33 \%$. 


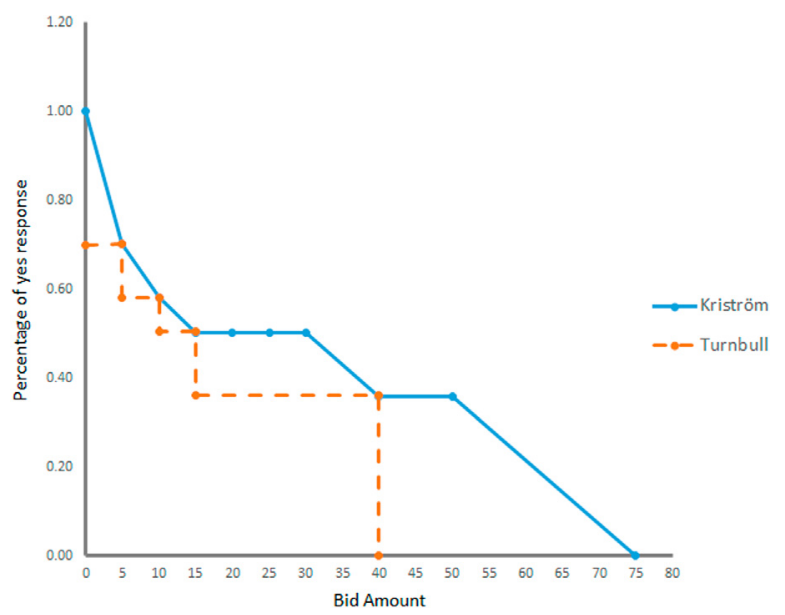

Fig. 1. Turnbull and Kriström (1990) nonparametric willingness-to-pay functions.

CVM literature. In virtually all published CVM studies with a dichotomous choice WTP question the bid value has a negative effect on the proportion of "yes" responses. This may be a result of publication bias, as studies with negative results go unpublished due to (1) authors not submitting these papers or (2) negative peer review. Yet, given the large number of published studies that pass the most basic dichotomous choice CVM validity test, the data used by ECD appear to be an outlier.

The Turnbull WTP estimate is appropriate for policy analysis where a lower bound estimate is needed. The Turnbull WTP is less appropriate for validity testing except as the lower bound in a sensitivity analysis around a "best" estimate of central tendency. The conclusion drawn by Egan et al. (2015) is that annual payments are superior to one-time payments because they are convergent valid with consumer surplus from a recreation demand model. The CVM data from Egan et al. (2015) provide a WTP estimate sufficient to support a policy recommendation that benefits exceed costs but do not support their conclusion that annual payments are preferred in CVM scenarios. Further research is necessary before a conclusion can be approached on this important issue.

\section{Appendix A. Supporting information}

Supplementary data associated with this article can be found in the online version at http://dx.doi.org/10.1016/j.jeem. 2016.09.004.

\section{References}

Aizaki, Hideo, Nakatani, Tomoaki, Sato, Kazuo, 2015. Stated Preference Methods Using R. CRC Press.

Boman, Mattias, Bostedt, G.öran, Kriström, Bengt, 1999. Obtaining welfare bounds in discrete-response valuation studies: a non-parametric approach. Land Econ., 284-294.

Egan, Kevin J., Corrigan, Jay R., Dwyer, Daryl F., 2015. Three reasons to use annual payments in contingent valuation surveys: convergent validity, discount rates, and mental accounting. J. Environ. Econ. Manag.

Haab, Timothy C., McConnell, Kenneth E., 2002. Valuing Environmental and Natural Resources: The Econometrics of Non-market Valuation. Edward Elgar Publishing.

Kriström, Bengt, 1990. A non-parametric approach to the estimation of welfare measures in discrete response valuation studies. Land Econ. 66 (2), 135-139.

Parsons, George R., Kelley, Myers, 2016. Fat tails and truncated bids in contingent valuation: an application to an endangered shorebird species. Ecol. Econ. 129, 210-219. 